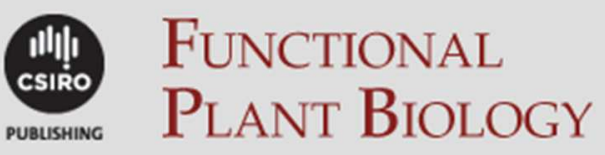

\title{
Rapid changes in root HvPIP2;2 aquaporins abundance and ABA concentration are required to enhance root hydraulic conductivity and maintain leaf water potential in response to increased evaporative demand
}

\begin{tabular}{|r|l|}
\hline Journal: & Functional Plant Biology \\
\hline Manuscript ID & FP16242.R1 \\
\hline Manuscript Type: & Research paper \\
\hline Date Submitted by the Author: & 20 -Sep-2016 \\
\hline Complete List of Authors: & $\begin{array}{l}\text { Veselov, Dmitry; Institute of Biology Ufa SC RAS, Plant Physiology } \\
\text { Sharipova, Guzel; Institute of Biology Ufa SC RAS, Plant Physiology } \\
\text { Veselov, Stanislav; Baskirskij Gosudarstvennyj Universitet, Biology } \\
\text { Dodd, Ian; University of Lancaster, Dept of Biological Sciences } \\
\text { Ivanov, Igor; Institute of Biology Ufa SC RAS, Plant Physiology } \\
\text { Kudoyarova, Guzel; Institute of Biology Ufa SC RAS, Plant Physiology }\end{array}$ \\
\hline Keyword: & Abscisic acid, Aquaporins, Hydraulic conductivity, Water relations \\
\hline
\end{tabular}


1 Rapid changes in root HvPIP2;2 aquaporins abundance and ABA concentration are 2 required to enhance root hydraulic conductivity and maintain leaf water potential in 3 response to increased evaporative demand

4

5 Dmitry S. Veselov ${ }^{A}$, Guzel V. Sharipova ${ }^{A}$, Stanislav Yu. Veselov ${ }^{B}$, Ian C. Dodd ${ }^{C}$, Igor Ivanov ${ }^{A}$, 6 Guzel R. Kudoyarova ${ }^{A, D}$

$7 \quad{ }^{\text {A }}$ Ufa Institute of Biology of Russian Academy of Sciences, 450054 Ufa, Russia

$8 \quad{ }^{B}$ Biological Faculty of Bashkir State University, 450073, Ufa Russia

$9{ }^{\mathrm{C}}$ Lancaster Environment Centre, Lancaster University, Lancashire LA1 4YQ, UK

10 D Corresponding author. Email: guzel@ anrb.ru 
14 Abstract. To address the involvement of abscisic acid (ABA) in regulating transpiration and root 15 hydraulic conductivity $\left(\mathrm{Lp}_{\mathrm{Root}}\right)$ and their relative importance for maintaining leaf hydration, the 16 ABA-deficient barley mutant Az34 and its parental wild-type (WT) genotype (cv. Steptoe) were 17 grown in hydroponics and exposed to changes in atmospheric vapour pressure deficit (VPD) 18 imposed by air warming. WT plants were capable of maintaining leaf water potential $\left(\Psi_{L}\right)$ that 19 was likely due to increased $L p_{\text {Root }}$ enabling higher water flow from the roots, which increased in 20 response to air warming. The increased $L p_{\text {Root }}$ and immunostaining for HvPIP2;2 aquaporins 21 correlated with increased root ABA content of WT plants when exposed to increased air 22 temperature. The failure of Az34 to maintain $\Psi_{L}$ during air warming may be due to lower $\operatorname{Lp} p_{\text {Root }}$ 23 than WT plants, and an inability to respond to changes in air temperature. The correlation 24 between root $\mathrm{ABA}$ content and $\mathrm{Lp}_{\text {Root }}$ was further supported by increased root hydraulic 25 conductivity in both genotypes when treated with exogenous ABA $\left(10^{-5} \mathrm{M}\right)$. Thus the ability of 26 the root system to rapidly regulate ABA levels (and thence aquaporin abundance and hydraulic 27 conductivity) seems important to maintain leaf hydration.

28

29 Additional keywords: Hordeum vulgare L., absicisic acid, tissue hydration, water relations. 


\section{Introduction}

32 Maintaining tissue hydration is of pivotal importance for plant survival under a changing 33 environment. This is achieved by fine regulation of leaf water relations, which is largely 34 dependent on coordinated changes in stomatal and hydraulic conductivity (Meinzer 2002). 35 Although both mechanisms are important for maintaining the balance between water uptake and losses, the former has attracted much more attention (Dodd, 2005; 2013 and references therein).

The discovery of the membrane located water channel proteins aquaporins, whose activity alters hydraulic conductivity (Maurel et al. 2008; Chaumont and Tyerman, 2014), led to an increase in research addressing the control of plant water uptake. The plant hormone abscisic acid (ABA), whose concentration increases in response to water deficit, can influence both stomatal (see ref. in review of Dodd 2005) and root and shoot hydraulic conductivity (Hose et al. 2000; Pantin et al. 2013), the latter effect being due to ABA-induced increase in activity of aquaporins (Parent et al. 2009). Thus the same hormone can induce opposite influences on water relations by either decreasing water flow due to stomatal closure, or increasing it by modulating hydraulic conductivity. The resulting effect may depend on the site of $\mathrm{ABA}$ accumulation in stressed plants: foliar ABA accumulation directly closes the stomata (McAdam et al 2016) and reduces transpiration by decreasing leaf hydraulic conductivity (Pantin et al. 2013), while root ABA accumulation increases hydraulic conductivity in a dose-dependent manner (Hose et al. 2000; Kudoyarova et al. 2011; Dodd 2013).

When plants experience a sudden increase in evaporative demand (eg. by warming the air that surrounds them), increased root $\mathrm{ABA}$ concentration was correlated with increased root hydraulic conductivity (Kudoyarova et al. 2011). However, using ABA-deficient or ABAoverproducing plants provides more specific evidence that ABA regulates root hydraulic conductivity and maintains leaf water relations. Genetic modification of ABA levels caused long lasting effects on plant hydraulic properties and aquaporin activity in maize (Parent et al. 2009) and tomato (Thompson et al. 2007) plants. However, the role of ABA in regulating plant water relations is likely to be most critical in response to abrupt step-changes in environmental conditions. Thus we compared leaf water relations, AQPs abundance and ABA content and localization in roots of the ABA deficient barley mutant (Az34) and its parental line cv. Steptoe

60 in response to air heating (that increased evaporative demand). The goal of the work was to 61 check the ability of the root system to rapidly regulate ABA levels (and thence hydraulic conductivity) and its importance to maintain leaf hydration. 
65 Seedlings of barley Hordeum vulgare L. (ABA deficient mutant Az34 and its wild-type cv. 66 Steptoe) were grown in 3-litre containers filled with 0.1 strength Hoagland-Arnon nutrient 67 solution under illumination of $400 \mu \mathrm{mol} \mathrm{m} \mathrm{m}^{-2}$ from ZN and DNAT-400 fluorescent lamps, at a 68 14-h photoperiod (from 8:00 to $22: 00$ ), $24^{\circ} \mathrm{C}$ air temperature and $40 \%$ relative air humidity 69 (which corresponds to VPD of $2 \mathrm{kPa}$ ). When plants were 7-d-old and bearing one true leaf that 70 was half-expanded, the air temperature was increased by $4^{\circ} \mathrm{C}$ from $24^{\circ} \mathrm{C}$ to $28^{\circ} \mathrm{C}$ (increase in 71 VPD from 2 up to $2.6 \mathrm{kPa}$ ) and maintained at that level for 1 hour using a fan-heater, taking care not to direct the airflow directly on to the shoots. Experiments started at 11:00.

Transpiration was measured as a loss of weight during 15 min by 10 intact plants drawing water from $50 \mathrm{ml}$ of nutrient solution in a container covered with aluminium foil to minimise surface evaporation. Stomatal conductance was determined with a porometer Model AP4, Delta T Devices, United Kingdom).

Leaf water potential $\left(\Psi_{L}\right)$ of tissue discs of $7 \mathrm{~mm}$ diameter were punched from mature leaves, placed immediately on clean sample holders and wrapped in aluminium foil to minimize water losses. After 16 discs had been collected (approximately $15 \mathrm{~min}$ ), they were unwrapped and then loaded into C52 chambers (Wescor Inc., Logan, UT, USA), incubated for $2 \mathrm{~h}$ then voltages were read with a microvoltmeter (model HR-33T-R; Wescor Inc., Logan, UT, USA). Voltages were converted into water potentials based on calibration with salt solutions of known osmotic potential.

Xylem sap flow from detached root systems was measured according to Carvajal et al. (1996) with modifications described by Veselov et al. (2008) and Vysotskaya et al. (2004). Applying the method for measuring $L p_{\text {Root }}$ in plants after air heating is described in detail by Kudoyarova et al. (2011). In short, the aerial parts of the plant were removed leaving a cylinder of leaf bases. These were connected to thin pre-weighed capillaries by means of silicon tubing. Xylem sap flow was measured in this way at $20^{\circ} \mathrm{C}$ for all plants. After $1 \mathrm{~h}$, the capillary containing osmotically-driven xylem sap was disconnected from the root system and weighed. The procedure was started after transpiration had stabilized following air heating (normally after $40 \mathrm{~min}$ ). Xylem sap flow was measured in this way for all plants (either control i.e. kept at $24{ }^{\circ} \mathrm{C}$ all the time or exposed to $28{ }^{\circ} \mathrm{C}$ for about $\left.40 \mathrm{~min}\right)$. In some cases ABA $\left(10^{-5} \mathrm{M}\right)$ was added to the nutrient solution of control Az34 and Steptoe plants 15 min before the start of sap collection and was present in the solution during xylem sap collection. Bleeding sap from each capillary was diluted five times to provide sufficient sample for measurement of osmotic potential using a freezing point depression osmometer (Osmomat 030, Germany). In preliminary experiments, proportionality of the effect of dilution on the obtained values was checked. Root hydraulic conductivity, Lp $p_{\text {Root }}$ was calculated according to equation: $L p_{R o o t}=J /\left(\left(\Psi_{s}-\Psi_{x}\right) x F W\right)$ where $J$ is 
100 the bleeding sap flow rate and $\left(\Psi_{s}-\Psi_{x}\right.$, ) the difference in osmotic pressure between xylem sap 101 and root medium and FW is the root fresh weight: a root solute reflection coefficient of 1.0 was 102 used (Knipfer and Fricke 2010). Because roots were dipped in 0.1 strength Hoagland-Arnon 103 nutrient solution with near-zero osmolality, the gradient of osmotic pressure was equal to $\Psi_{x}$.

104 To inhibit AQP activity, hydroxyl radicals $(* \mathrm{OH})$ were produced through the Fenton reaction $105\left(\mathrm{Fe}^{2+}+\mathrm{H}_{2} \mathrm{O}_{2}=\mathrm{Fe}^{3+}+\mathrm{OH}^{-}+{ }^{*} \mathrm{OH}\right)$ by mixing equal volumes of $6 \mathrm{mM} \mathrm{H}_{2} \mathrm{O}_{2}$ and $6 \mathrm{mM} \mathrm{FeSO} 4(\mathrm{Ye}$ 106 and Steudle 2006).

107 Excised roots might have lower Lr as shown by Vandeleur et al (2014) since the measured 108 values of hydraulic conductivity are the result of osmotically induced flow rather than 109 hydrostatic induced flow. However, since osmotically driven flow depends on aquaporins, our 110 measurements seems appropriate within the context of the research problem posed

111 ABA was immunoassayed as previously described (Vysotskaya et al. 2009) in the roots of 112 control plants (continuously kept at $24{ }^{\circ} \mathrm{C}$ ) and exposed to air heating (after transpiration had 113 stabilised about $40 \mathrm{~min}$ after the start of experiment). Aqueous residues of ethanol extracts were 114 diluted with distilled water, acidified with $\mathrm{HCl}$ to $\mathrm{pH} 2.5$ and partitioned twice with peroxide115 free diethyl ether (ratio of organic to aqueous phases was 1:3). Subsequently hormones were

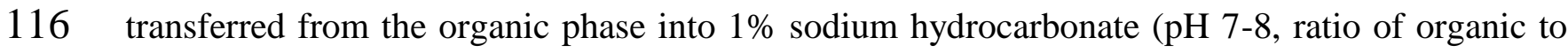
117 aqueous phases was 3:1), re-extracted with diethyl ether after acidification to $\mathrm{pH} 2.5$, methylated 118 with diazomethane and immunoassayed using antibodies to ABA (Veselov et al. 1992). ABA 119 recovery calculated in model experiments was about 80\%. Reducing the amount of extractant, 120 based on the calculated distribution of ABA in organic solvents, increased the selectivity of 121 hormone recovery and the reliability of immunoassay. The reliability of the immunoassay for 122 ABA was enabled by both specificity of antibodies and purification of hormones according to a 123 modified scheme of solvent partitioning (Veselov et al. 1992).

124 For immunolocalization of AQPs, root sections were harvested from control Steptoe and 125 Az34 plants. Root tip segments 3-5 mm in length were fixed in 4\% carbodiimide (1-ethyl-3-(3126 dimethylaminopropyl) carbodiimide, Sigma, United States) for $4 \mathrm{~h}$ as described earlier 127 (Sharipova et al. 2016). Tissues were infiltrated with carbodiimide under vacuum during the first $12830 \mathrm{~min}$ of fixation. After dehydration in ethanol solutions of increasing grades (up to 96\%), 129 samples were embedded in the methacrylate resin (JB-4, Electron Microscopy Sciences, United 130 States) as recommended by manufacturers. Histological sections (1.5 $\mu \mathrm{m}$ thickness) were cut 131 with the rotation microtome (HM 325, MICROM Laborgerate, Germany) and placed on slides. 132 Immunolocalization was performed as described earlier (Sharipova et al. 2016). Sections were 133 treated with $0.1 \mathrm{M} \mathrm{Na-phosphate} \mathrm{buffer}(\mathrm{pH} 7.3$ ) containing $0.2 \%$ gelatin and $0.05 \%$ Tween 20 134 (PGT) for $30 \mathrm{~min}$. Rabbit anti-ABA serum $(20 \mu \mathrm{l})$, and diluted with PGT at the ratio of $1: 80$, 
135 was poured on some sections. To check specificity of immunostaining, other sections were

136 treated with non-immune serum at similar dilution. Sections were covered with $50 \mu 10.1 \mathrm{M}$

137 phosphate buffer ( $\mathrm{pH} 7.2-7.4)$ with $0.2 \%$ gelatine and $0.05 \%$ Tween 20 (PGT) and incubated for

$13830 \mathrm{~min}$ in a moist chamber. Serum and gold conjugates were diluted with PGT. Sections washed

139 with distilled water were incubated with immune serum to HvPIP2;1, HvPIP2;2 and HvPIP2;5

140 aquaporins for $2 \mathrm{~h}$ in a moist chamber. Polyclonal antibodies for HvPIP2s were raised in rabbits

141 against synthetic oligopeptides (Medical \& Biological Laboratories Co., Japan) corresponding to

142 the amino acid sequences in the N- region of HvPIP2;1 (Katsuhara et al. 2002), HvPIP2;2 (Horie

143 et al. 2011), and HvPIP2;5 (Sharipova et al., 2016). Control sections were treated with rabbit

144 nonimmune serum. To visualize serum binding with aquaporins, sections were treated with gold

145 conjugate (BBInt, United Kingdom) for $1 \mathrm{~h}$ in a moist chamber. After three washes with PT

146 samples were incubated with silver enhancer (BBInt, United Kingdom) for 15-20 min in dark

147 and examined under a light microscope. Excess silver was removed with distilled water.

148 Preparations were visualized under an Axio Imager.A1 light microscope (Carl Zeiss Jena,

149 Germany) equipped with an AxioCam MRc5 digital camera (Carl Zeiss Jena, Germany).

150 Intensity of immunostaining of plasmalemma aquaporins was estimated from 8-bit 151 grayscale images using ImageJ software (v.1.48, National Institutes of Health). Staining values,

152 obtained by determining the pixel intensity, were averaged for each root section (about 160

153 circles per image of one root section). Intensity of root section staining was measured by using

154 the "Freehand Selections" Tool of the same software by selecting the entire area of root sections

155 and measuring mean pixel intensities within the region of interest. Images were taken from 9

156 independent sections per genotype or temperature-treatment. Intensity of staining was expressed

157 in arbitrary units, maximal staining of circles within root section images was taken as $100 \%$,

158 while minimal staining was $0 \%$.

159 Significant differences between treatments were determined by employing an analysis of

160 variance (ANOVA) using the Excel software. The least squares difference (LSD) test was

161 performed to discriminate significant $(\mathrm{p}<0.05)$ treatment differences.

162 Results

163 Transpiration of Az34 plants was initially $45 \%$ higher than in Steptoe plants (Fig. 1). Air heating

164 increased transpiration rate of Steptoe and Az34 plants by $39 \%$ and $25 \%$ respectively with

165 Steptoe plants ultimately transpiring at the same rate as Az34 plants under control conditions.

166 Stomatal conductance of Steptoe and Az34 plants was about 55 and $70 \mathrm{mmol} \mathrm{m}^{-2} \mathrm{~s}^{-1}$, 167 respectively (statistically different at $\mathrm{p}<0.05, \mathrm{n}=10$ ) and did not change significantly with the air 168 warming. 
169 Leaf water potential $\left(\Psi_{\mathrm{L}}\right)$ was measured after transpiration stabilized about 40 min after the 170 start of air heating. Leaf water potential of Az34 was $0.32 \mathrm{MPa}$ lower than that of parental cv. 171 Steptoe under control conditions, and decreased by another $0.23 \mathrm{MPa}$ with the increase in air 172 temperature, while it did not significantly change in Steptoe plants (Table 1).

Xylem sap flowed from detached WT roots about 2 times faster than in Az34 (Fig. 2a). Air

174 heating increased the flow rate from WT roots by about 1.5 times but did not influence that of 175 Az34. Adding ABA to the nutrient solution of Az34 plants increased xylem sap flow rate 2.6176 fold. The increase in Steptoe was of less magnitude (only 1.6-fold), but also statistically 177 significant. Since the driving force for osmotically driven flow of xylem sap was the same in 178 both genotypes and did not change significantly with air heating (Table 1), a similar pattern of 179 Lp Root was detected in the plants: lower level in Az34 plants, increase in Steptoe with the air 180 heating and no response to air heating in Az34 plants (Fig. 2b). Adding ABA to the nutrient 181 solution increased L $p_{\text {Root }}$ of both Az34 and Steptoe plants. Thus ABA treatment increased L $p_{\text {Root }}$ 182 of Steptoe plants kept at control temperature to the level of heated Steptoe plants, while this 183 exogenous hormone increased $\mathrm{Lp}_{\text {Root }}$ of Az34 plants to the level of Steptoe control plants. 184 Inhibiting AQP activity by producing reactive hydroxyl radicals during the Fenton reaction 185 decreased hydraulic conductivity of both genotypes, however the extent of decline was greater in 186 the plants under air warming suggesting that AQPs contribute to the increased hydraulic conductivity under this treatment (Table 1).

188 In Steptoe plants changes in transpiration induced by air warming strongly correlated with 189 the increase in hydraulic conductivity ( $\mathrm{r}=0.87)$, while in the case of Az34 the correlation was 190 moderate $(\mathrm{r}=0.56)$.

191 Bulk root ABA concentration of Steptoe plants was 50\% higher than in Az34 plants and 192 further increased with air heating (Fig. 3). No significant changes in ABA content were detected 193 in the roots of Az34 plants following air warming.

194 Air warming increased immunostaining for HvPIP2;2 aquaporins in the roots of Steptoe

195 (Fig. 4, Table 3), but no such effect was detected in Az34. Increased air temperature did not 196 affect the abundance of HvPIP2;1 or HvPIP2;5 aquaporins in either Az34 or Steptoe roots.

\section{Discussion}

199 Previous experiments have addressed long-term effects (days to weeks) of ABA deficiency on 200 leaf elongation and stomatal conductance of barley plants exposed to dry or compacted soil 201 (Mulholland et al. 1996; Martin-Vertedor and Dodd, 2011). In accordance with these earlier 202 reports, leaf water potential $\left(\Psi_{L}\right)$ was lower in Az34 than WT plants (Table 1), likely due to the 
203 higher transpiration rate of Az34 plants (Fig. 1). The latter effect is apparently explained by 204 ABA's ability to close stomata and its reduced level in ABA deficient Az34 plants (Mulholland 205 et al. 1996; Martin-Vertedor and Dodd, 2011). Although air warming increased transpiration of 206 Steptoe plants almost to the level of Az34 plants (measured before air warming - Fig. 1), $\Psi_{L}$ of 207 Steptoe was not decreased by this treatment (Table 1). This suggests that the lower $\Psi_{L}$ of Az34 208 was not entirely due to altered stomatal behaviour.

209 Previously, air warming increased transpiration of wheat plants several-fold (Kudoyarova 210 et al. 2011), which was due to increased stomatal conductance. Transpiration increased to a 211 lesser extent (20-30\% - Fig. 1) in both barley genotypes (due to the absence of changes in 212 stomatal conductance) and caused a drop in leaf water potential in Az34 plants but no effect in 213 Steptoe (Table 1). This suggests that elevated transpiration of Steptoe plants was balanced by 214 higher water flow from the roots, which was supported experimentally by measuring xylem sap 215 flow from the roots (Fig. 2). While air warming increased xylem flow in Steptoe plants, there 216 was no change in Az34 plants, suggesting impaired functionality of the ABA-deficient barley 217 roots.

218 Experiments with both exogenous ABA application to roots (Hose et al. 2000), and 219 transgenic ABA-overproducing plants (Thompson et al. 2007) have shown that increased ABA 220 concentrations result in increased root hydraulic conductance. In agreement, hydraulic 221 conductance of both genotypes was increased by exogenous ABA in the present experiments 222 (Fig. 2). Consequently the increased hydraulic conductivity and abundance of PIP2;2 detected in 223 Steptoe roots under air warming and the lack of response in Az34 is likely related to the 224 increased root ABA concentration of the former and to the unchanged ABA levels of the latter 225 (Fig. 3). ABA involvement in modulating aquaporin abundance in barley plants is supported by 226 experiments demonstrating increased PIPs abundance in ABA treated roots of Az34 and Steptoe 227 plants (Sharipova et al., 2016).

228 Perturbed water relations are characteristic of ABA deficient plants, and most frequently 229 explained by their failure to control stomatal conductance (Neil and Horgan 1985; Makela et al. 230 2003). ABA is important in this respect under conditions that require stomatal closure to 231 maintain leaf water status. On the contrary, adaptation to increased air temperature demands 232 maintaining high transpiration rates to allow plant cooling (Reynolds et al., 1998). Under high 233 evaporative demand, increased root hydraulic conductance may serve as the main mechanism 234 increasing water flow from the roots thereby maintaining increased transpiration (Tardieu et al. 235 2010). Previous experiments with inhibition of phloem transport have shown that under air 236 warming, root ABA accumulation was mainly the outcome of increased export from the shoots 
237 (Kudoyarova et al., 2011). Thus ABA-controlled changes in (root) hydraulic conductivity is also 238 of great importance for maintaining water balance of the plants.

Molecular genetic approaches allow manipulation of ABA level (e.g. transgenic plants 240 overproducing ABA - Thompson et al. 2007) but negative effects of ABA on plant productivity 241 may be expected since crop yield is often positively related to transpiration (Collins et al. 2008; 242 Blum, 2015). However experiments with tomato plants overproducing ABA showed that 243 increased ABA levels may improve water supply to the shoot, thereby maintaining water status 244 when evaporative demand is high (Thompson et al. 2007). Thus ABA may act as a growth245 promoter via its effect on aquaporin activities, which is expected to have a greater influence 246 under high evaporative demand (Tardieu et al. 2010). Our results confirm these suggestions by 247 showing that sufficient ABA is necessary to adequately control root hydraulic conductivity 248 (Lp $\left.\mathrm{poot}_{\mathrm{R}}\right)$ in barley following a step-change in VPD under air warming.

\section{Acknowledgments}

The specific antibodies against HvPIP2 aquaporins was a gift from Prof. Maki Katsuhara (Okayama University, Japan). This work was supported by grant of the Russian Foundation for

\section{References}

256 Blum A (2015) Towards a conceptual ABA ideotype in plant breeding for water limited environments. Functional Plant Biology 42, 502-513.

Carvajal M, Cooke DT, Clarkson DT (1996) Responses of wheat plants to nutrition deprivation may involve the regulation of water-channel function. Planta 199, 372-381.

260 Chaumont F, Tyerman SD (2014) Aquaporins: highly regulated channels controlling plant water relations. Plant Physiology 164, 1600-1618.

262 Collins NC, Tardieu F, Tuberosa R (2008) Quantitative trait loci and crop performance under abiotic stress: where do we stand? Plant Physiology 147, 469-486.

264 Dodd IC (2005) Root-to-shoot signalling: Assessing the roles of 'up' in the up and down world of long-distance signaling in planta. Plant \& Soil 274, 257-275.

266 Dodd IC (2013) Abscisic acid and stomatal closure: a hydraulic conductance conundrum? New Phytologist 197, 6-8.

268 Horie T, Kaneko T, Sugimoto G, Sasano S, Panda SK, Shibasaka M, Katsuhara M (2011) Mechanisms of water transport mediated by PIP aquaporins and their regulation via phosphorylation events under salinity stress in barley roots. Plant \& Cell Physiology 52, 663-675. 
272 Hose E, Steudle E, Hartung W (2000) Abscisic acid and hydraulic conductance of maize roots: a study using cell- and root-pressure probes. Planta 211, 874-882.

274 Katsuhara M, Akiyama Y, Koshio K, Shibasaka M, Kasamo K (2002) Functional analysis of water channels in barley roots. Plant \& Cell Physiology 43, 885-893.

276 Knipfer T, Fricke W (2011) Water uptake by seminal and adventitious roots in relation to wholeplant water flow in barley (Hordeum vulgare L.). Journal of Experimental Botany 62, 717-733.

Makela P, Munns R, Colmer TD, Peltonen-Sainio P (2003) Growth of tomato and an ABAdeficient mutant (sitiens) under saline conditions. Physiologia Plantarum 117, 58-63.

Martin-Vertedor AI, Dodd IC (2011) Root-to-shoot signalling when soil moisture is heterogeneous: increasing the proportion of root biomass in drying soil inhibits leaf growth and increases leaf abscisic acid concentration. Plant, Cell \& Environment 34, $1164-1175$.

Maurel C, Verdoucq L, Luu DT, Santoni V (2008) Plant aquaporins: membrane channels with multiple integrated functions. Annual Review of Plant Biology 59, 595-624.

McAdam SAM, Sussmilch FC, Brodribb TJ (2016) Stomatal responses to vapour pressure deficit are regulated by high speed gene expression in angiosperms. Plant, Cell \& Environment 39, 485-491.

Meinzer FG (2002) Co-ordination of vapour and liquid phase water transport properties in plants. Plant, Cell \& Environment 25, 265-274.

Mulholland BJ, Taylor B, Black CR, Roberts JA (1996) Effect of soil compaction on barley (Hordeum vulgare L.) growth II. Are increased xylem sap ABA concentrations involved in maintaining leaf expansion in compacted soils? Journal of Experimental Botany 47, $551-556$.

Parent B, Hachez C, Redondo E, Simonneau T, Chaumont F, Tardieu F (2009) Drought and abscisic acid effects on aquaporin content translate into changes in hydraulic conductance and leaf growth rate: a trans-scale approach. Plant Physiology 149, 2000-2012. 
306 Reynolds MP, Singh RP, Ibrahim A, Ageeb OA, Larque-Saavedra A, Quick JS (1998) 307 Evaluating physiological traits to complement empirical selection for wheat in warm environments. Euphytica 100, 85-94.

Sharipova G, Veselov D, Kudoyarova G, Fricke W, Dodd IC, Katsuhara M, Furuichi T, Ivanov I, Veselov S (2016) Exogenous application of abscisic acid (ABA) increases root and cell hydraulic conductivity and abundance of some aquaporin isoforms in the ABA-deficient barley mutant Az34. Annals of Botany. doi:10.1093/aob/mcw117

Tardieu F, Parent B, Simonneau T (2010) Control of leaf growth by abscisic acid: hydraulic or non-hydraulic processes? Plant, Cell \& Environment 33, 636-647.

Thompson AJ, Andrews J, Mulholland BJ, McKee JMT, Hilton HW, Horridge JS, Farquhar GR, Smeeton RC, Smillie IRA, Black CR, Taylor IB (2007) Overproduction of abscisic acid in tomato increases transpiration efficiency and root hydraulic conductance and influences leaf expansion. Plant Physiology 143, 1905-1917.

Vandeleur RK, Sullivan W, Athman A, Jordans C, Gilliham M, Kaiser BN, Tyerman SD (2014) Rapid shoot-to-root signalling regulates root hydraulic conductance via aquaporins. Plant Cell and Environment 37, 520-538.

Veselov DS, Sharipova GV, Veselov SU, Kudoyarova GR (2008) The effects of NaCl treatment on water relations, growth and $\mathrm{ABA}$ content in barley cultivars differing in drought tolerance. Journal of Plant Growth Regulation 27, 380-386.

Veselov S, Kudoyarova G, Egutkin N, Gyuli-Zade V, Mustafina A, Kof E (1992) Modified solvent partitioning scheme providing increased specificity and rapidity of immunoassay for indole 3-acetic acid. Physiologia Plantarum 86, 93-96.

Vysotskaya LB, Arkhipova TN, Timergalina LN, Dedov AV, Veselov SY, Kudoyarova GR (2004) Effect of partial root excision on transpiration, root hydraulic conductance and leaf growth in wheat seedlings. Plant Physiology \& Biochemistry 42, 251-255. of shoot cytokinin oxidase activity: assessing its impacts on cytokinin status and biomass allocation of nutrient deprived durum wheat. Functional Plant Biology 36, 66-72. 
336 Table 1. Leaf water potential $\left(\Psi_{1}\right)$ and gradient of osmotic potential $(\Delta \Psi)$-osmotic pressure 337

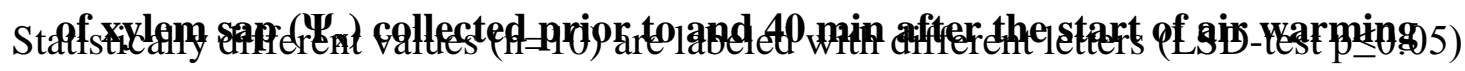

339

\begin{tabular}{lccc}
\hline Genotype & $\begin{array}{c}\text { Treatment time } \\
(\mathrm{min})\end{array}$ & $\Psi_{1}(\mathrm{MPa})$ & $\boldsymbol{\Psi}_{\mathbf{x}}$ \\
\hline Steptoe & 0 & $-0.57 \pm 0.08^{\mathrm{a}}$ & $0.32 \pm 0.01^{\mathrm{a}}$ \\
& 40 & $-0.43 \pm 0.05^{\mathrm{a}}$ & $0.25 \pm 0.03^{\mathrm{a}}$ \\
\hline Az34 & 0 & $-0.89 \pm 0.06^{\mathrm{b}}$ & $0.35 \pm 0.06^{\mathrm{a}}$ \\
& 40 & $-1.12 \pm 0.09^{\mathrm{c}}$ & $0.34 \pm 0.02^{\mathrm{a}}$ \\
\hline
\end{tabular}

340 
342 Table 2. Effect of inhibiting AQP activity by producing reactive hydroxyl radicals during 343 the Fenton reaction on root hydraulic conductance $\left(\mathrm{mg} \mathrm{h}^{-1} \mathrm{~g}^{-1}\right.$ root fresh weight $\left.\mathrm{MPa}^{-1}\right)$ of 344 roots excised from the barley plants prior to and 40 min after the start of air warming. 345 Significantly different means for each variable are labelled with different letters (n=5, LSD 346 test).

\begin{tabular}{|l|l|l|}
\hline Genotype, treatment & \multicolumn{1}{|c|}{ Control } & \multicolumn{1}{c|}{$\begin{array}{c}\text { Increased air } \\
\text { temperature }\end{array}$} \\
\hline Steptoe, - Fenton & $320 \pm 41^{\mathrm{c}}$ & $590 \pm 61^{\mathrm{d}}$ \\
\hline Az34, - Fenton & $130 \pm 19^{\mathrm{ab}}$ & $170 \pm 21^{\mathrm{b}}$ \\
\hline Steptoe, +Fenton & $165 \pm 22^{\mathrm{b}}$ & $280 \pm 31^{\mathrm{c}}$ \\
\hline Az34, +Fenton & $82 \pm 9^{\mathrm{a}}$ & $110 \pm 16^{\mathrm{ab}}$ \\
\hline
\end{tabular}



deficient (Az34) mutant and parental cv. (Steptoe)

352 Means \pm SE, arbitrary units, maximal staining of circles within section images was taken for 100

$353 \%$, while minimal staining was $0 \%$. Significantly different means for each variable are labelled

\begin{tabular}{lcccc}
\hline $\begin{array}{l}\text { Staining } \\
\text { for }\end{array}$ & Control & $\begin{array}{c}\text { Increased air } \\
\text { temperature }\end{array}$ & Control & $\begin{array}{c}\text { Ancreased air } \\
\text { temperature }\end{array}$ \\
\hline HvPIP2;1 & $25+7^{\mathrm{a}}$ & $29+4^{\mathrm{a}}$ & $29 \pm 8^{\mathrm{a}}$ & $31 \pm 14^{\mathrm{a}}$ \\
HvPIP2;2 & $20 \pm 6^{\mathrm{a}}$ & $71+9^{\mathrm{b}}$ & $31 \pm 7^{\mathrm{a}}$ & $25 \pm 12^{\mathrm{a}}$ \\
HvPIP2;5 & $69+9^{\mathrm{a}}$ & $57+7^{\mathrm{a}}$ & $59 \pm 11^{\mathrm{a}}$ & $49 \pm 15^{\mathrm{a}}$ \\
\end{tabular}




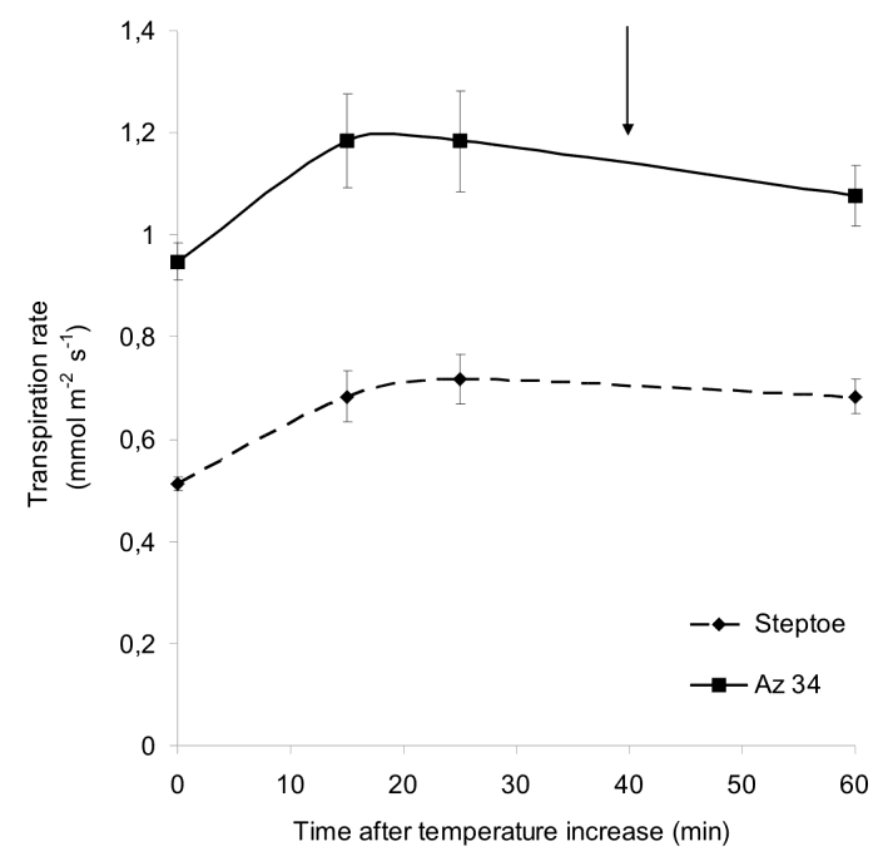

360 Fig. 1. Effect of air warming on transpiration (normalized to leaf area) of Steptoe and Az34 361 plants. Arrow indicates sampling time for ABA assay, root excision for hydraulic conductivity 362 measurements and tissue fixation for immunolocalization. Data are means \pm SE of 10 plants. 

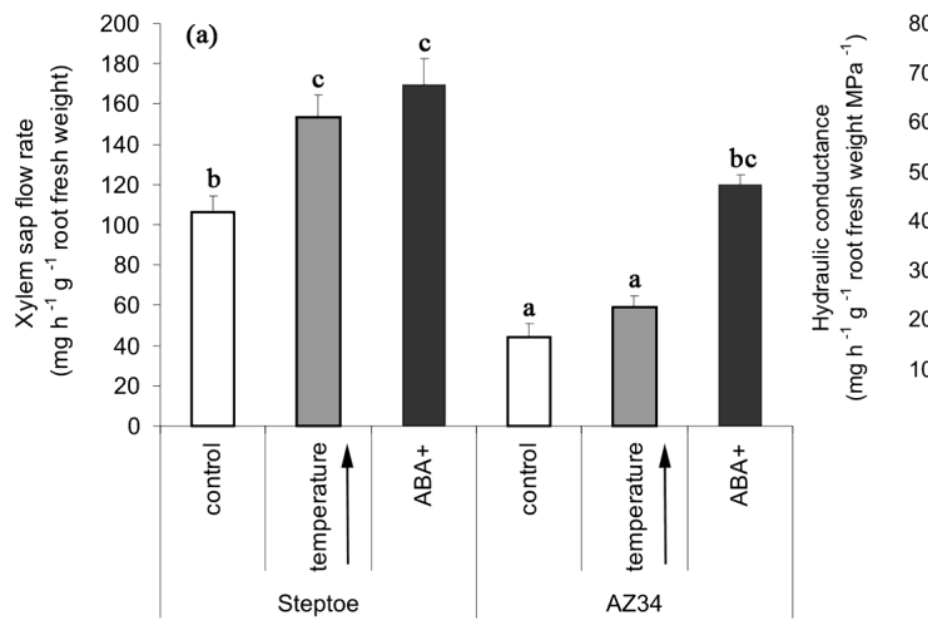

(b)

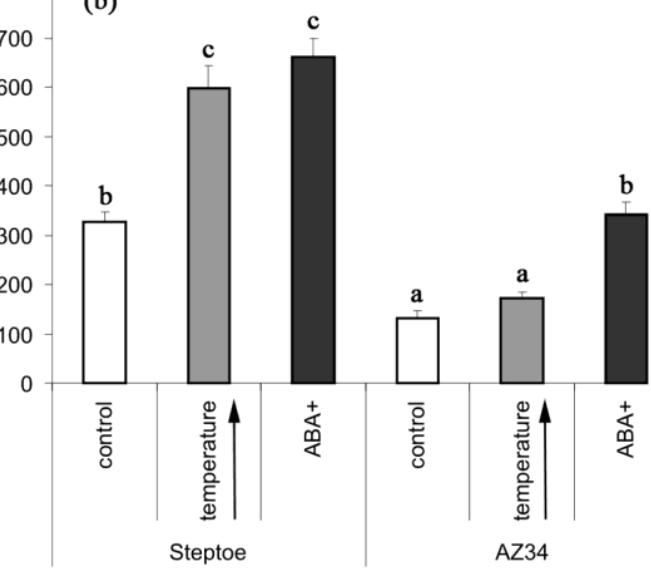

365 Fig. 2. Xylem sap flow (a), and root hydraulic conductivity (b) of Steptoe and Az34 plants 366 measured in control plants exposed to $24{ }^{\circ} \mathrm{C}$ and $40 \mathrm{~min}$ after the start of temperature increase 367 (temp). ABA $\left(10^{-5} \mathrm{M}\right)$ was added to the nutrient solution of control Steptoe and Az34 plants 20 $368 \mathrm{~min}$ before the start and was present in the nutrient solution during the time of xylem sap 369 collection. Statistically different values $(\mathrm{P}<0.05)$ are labeled with different letters 


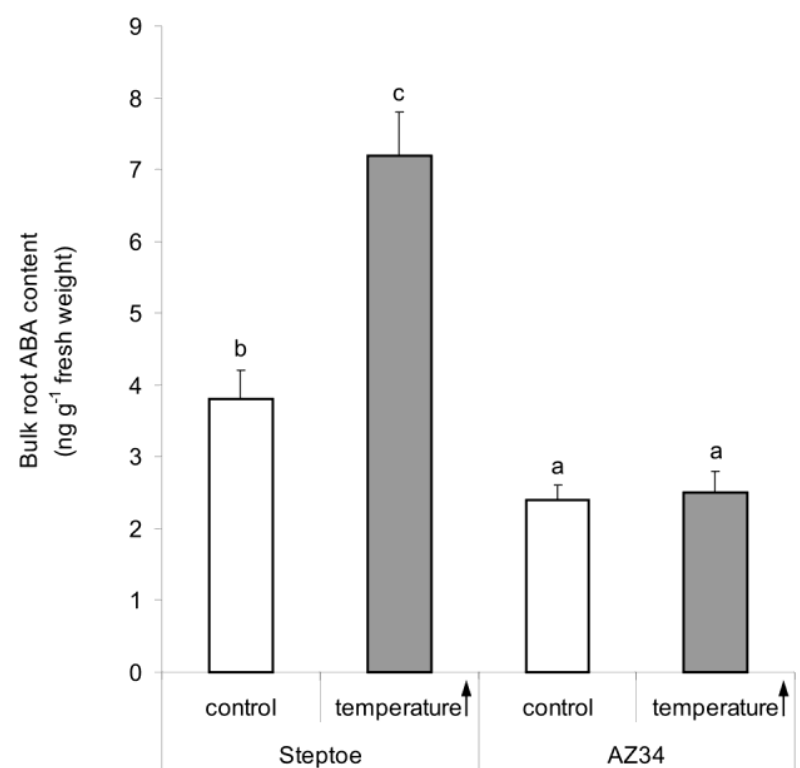

372 Fig. 3. Bulk root $\mathrm{ABA}$ content (mean values $\pm \mathrm{SE}, \mathrm{n}=5$ ) of Steptoe and Az34 plants measured in 373 control plants exposed to $24{ }^{\circ} \mathrm{C}$ and $40 \mathrm{~min}$ after the start of temperature increase (temp). 374 Statistically different values $(\mathrm{P}<0.05)$ are labeled with different letters 375 

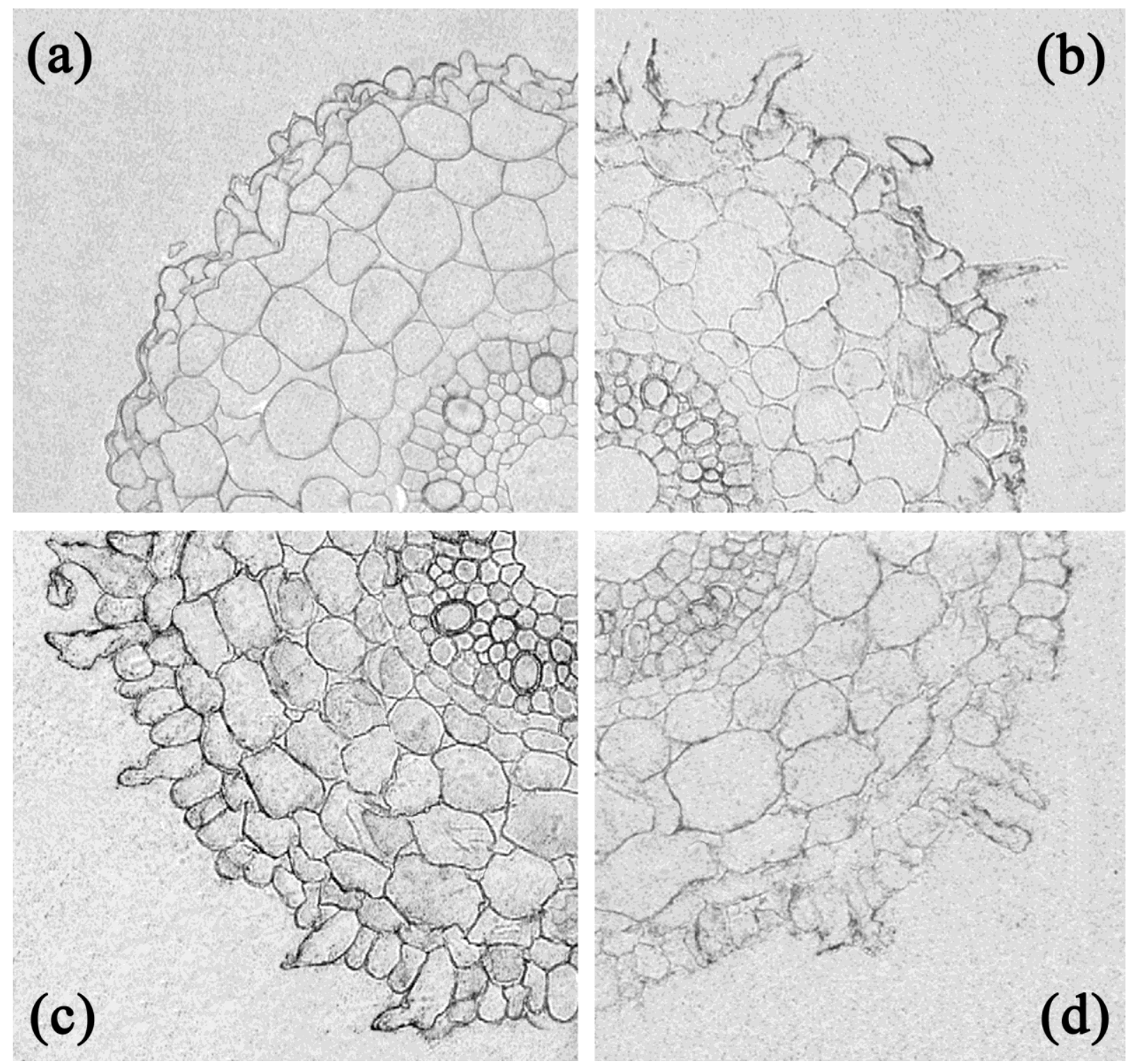

Fig. 4. Immunohistochemical localization of HvPIP2;2 AQPs in root sections (3-5 mm from the

378 tip where root hairs appeared) of Steptoe (a,c) and Az34 (b,d) plants. a,b - control plants; c,d 379 plants exposed to air warming for $40 \mathrm{~min}$. 
Table 1. Leaf water potential $\left(\Psi_{1}\right)$ and gradient of osmotic potential $(\Delta \Psi)$-osmotic pressure of xylem sap $\left(\Psi_{\mathrm{x}}\right)$ collected prior to and $40 \mathrm{~min}$ after the start of air warming Statistically different values $(n=10)$ are labeled with different letters (LSD-test $\mathrm{p} \leq 0.05)$

\begin{tabular}{lccc}
\hline Genotype & $\begin{array}{c}\text { Treatment time } \\
(\mathrm{min})\end{array}$ & $\Psi_{1}(\mathrm{MPa})$ & $\boldsymbol{\Psi}_{\mathbf{x}}$ \\
\hline Steptoe & 0 & $-0.57 \pm 0.08^{\mathrm{a}}$ & $0.32 \pm 0.01^{\mathrm{a}}$ \\
& 40 & $-0.43 \pm 0.05^{\mathrm{a}}$ & $0.25 \pm 0.03^{\mathrm{a}}$ \\
\hline Az34 & 0 & $-0.89 \pm 0.06^{\mathrm{b}}$ & $0.35 \pm 0.06^{\mathrm{a}}$ \\
& 40 & $-1.12 \pm 0.09^{\mathrm{c}}$ & $0.34 \pm 0.02^{\mathrm{a}}$ \\
\hline
\end{tabular}


Table 2. Effect of inhibiting AQP activity by producing reactive hydroxyl radicals during the Fenton reaction on root hydraulic conductance $\left(\mathrm{mg} \mathrm{h}^{-1} \mathrm{~g}^{-1}\right.$ root fresh weight $\left.\mathrm{MPa}^{-1}\right)$ of roots excised from the barley plants prior to and $40 \mathrm{~min}$ after the start of air warming. Significantly different means for each variable are labelled with different letters $(n=5$, LSD test).

\begin{tabular}{|l|l|l|}
\hline Genotype, treatment & \multicolumn{1}{|c|}{ Control } & \multicolumn{1}{c|}{$\begin{array}{c}\text { Increased air } \\
\text { temperature }\end{array}$} \\
\hline Steptoe, - Fenton & $320 \pm 41^{\mathrm{c}}$ & $590 \pm 61^{\mathrm{d}}$ \\
\hline Az34, - Fenton & $130 \pm 19^{\mathrm{ab}}$ & $170 \pm 21^{\mathrm{b}}$ \\
\hline Steptoe, + Fenton & $165 \pm 22^{\mathrm{b}}$ & $280 \pm 31^{\mathrm{c}}$ \\
\hline Az34, +Fenton & $82 \pm 9^{\mathrm{a}}$ & $110 \pm 16^{\mathrm{ab}}$ \\
\hline
\end{tabular}


Table 3. Intensity of staining for HvPIP2 aquaporins of control and treated of ABA deficient (Az34) mutant and parental cv. (Steptoe)

Means $\pm \mathrm{SE}$, arbitrary units, maximal staining of circles within section images was taken for 100 $\%$, while minimal staining was $0 \%$. Significantly different means for each variable are labelled with different letters $(n=9$, LSD test)

\begin{tabular}{lcccc}
\hline $\begin{array}{l}\text { Staining } \\
\text { for }\end{array}$ & Control & $\begin{array}{c}\text { Steptoe } \\
\text { Increased air } \\
\text { temperature }\end{array}$ & Control & $\begin{array}{c}\text { Az34 } \\
\text { Incmperature } \\
\text { temperair }\end{array}$ \\
\hline HvPIP2;1 & $25+7^{\mathrm{a}}$ & $29+4^{\mathrm{a}}$ & $29 \pm 8^{\mathrm{a}}$ & $31 \pm 14^{\mathrm{a}}$ \\
HvPIP2;2 & $20 \pm 6^{\mathrm{a}}$ & $71+9^{\mathrm{b}}$ & $31 \pm 7^{\mathrm{a}}$ & $25 \pm 12^{\mathrm{a}}$ \\
HvPIP2;5 & $69+9^{\mathrm{a}}$ & $57+7^{\mathrm{a}}$ & $59 \pm 11^{\mathrm{a}}$ & $49 \pm 15^{\mathrm{a}}$ \\
\hline
\end{tabular}




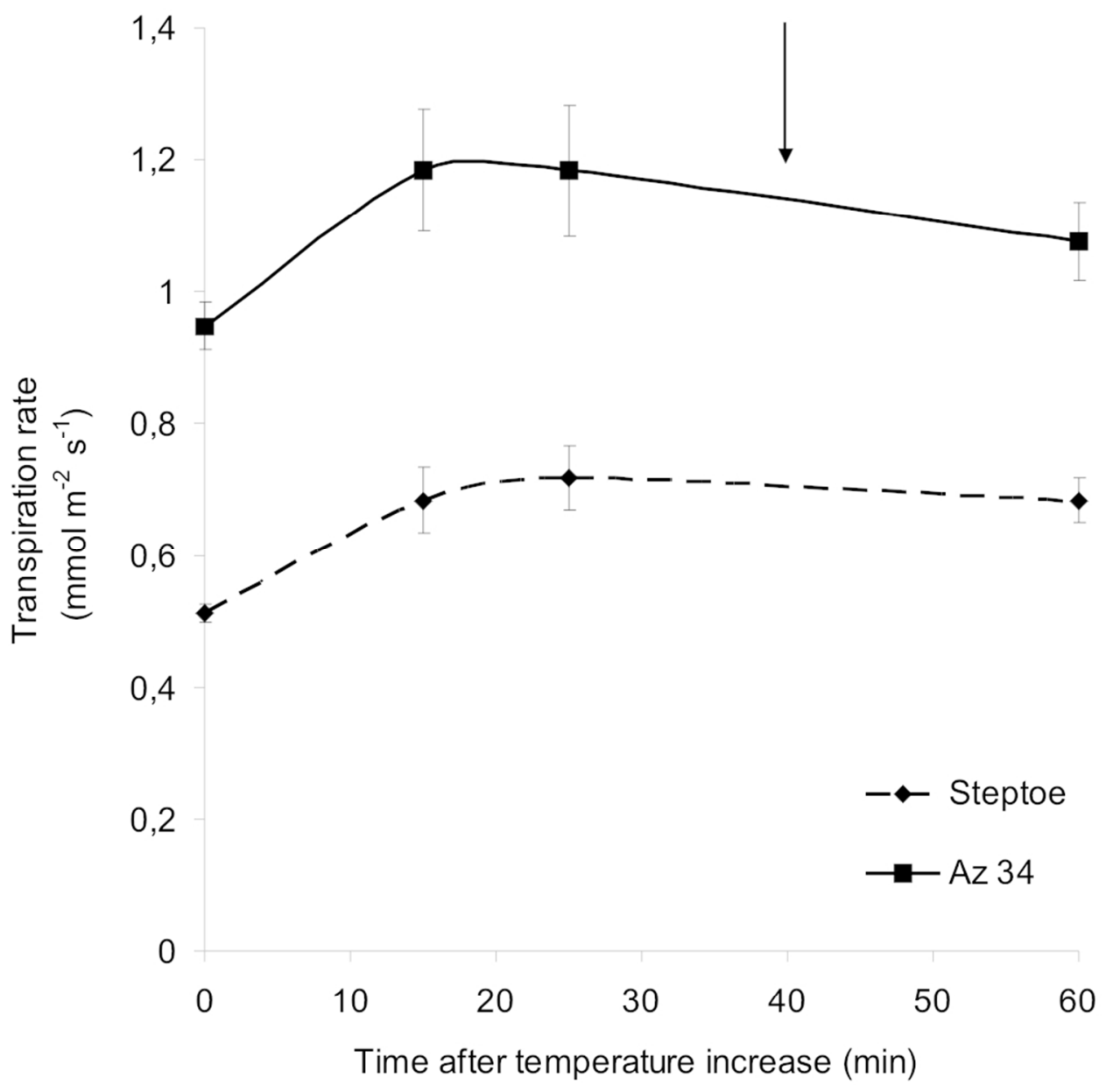

Effect of air warming on transpiration (normalized to leaf area) of Steptoe and Az34 plants. Arrow indicates sampling time for ABA assay, root excision for hydraulic conductivity measurements and tissue fixation for immunolocalization. Data are means \pm SE of 10 plants.

Fig. 1.

$89 \times 87 \mathrm{~mm}(300 \times 300 \mathrm{DPI})$ 

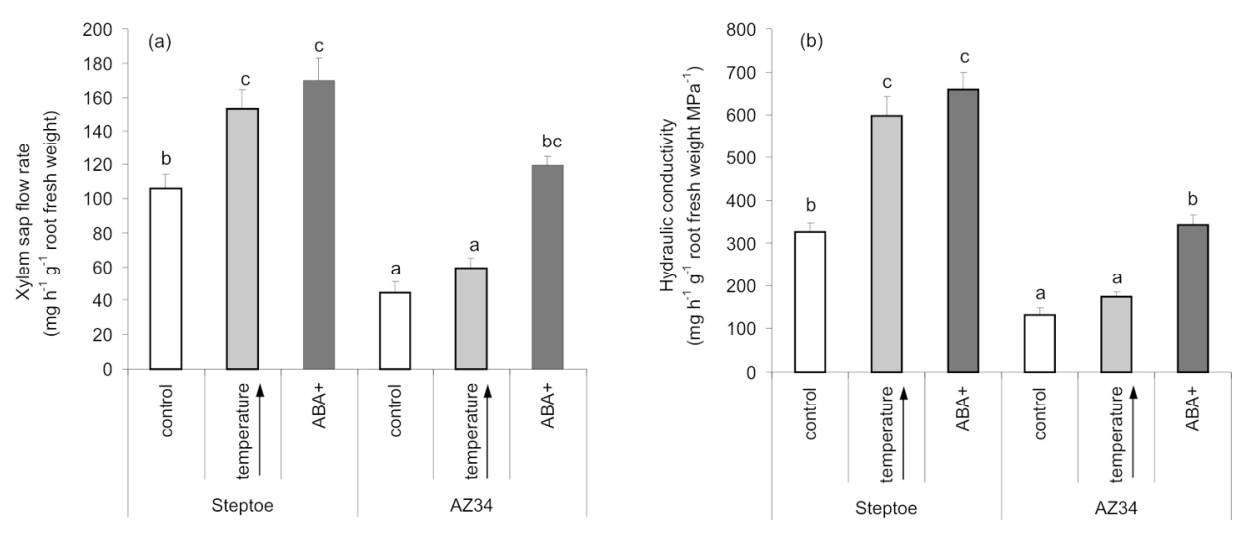

Xylem sap flow (a), and root hydraulic conductivity (b) of Steptoe and Az34 plants measured in control plants exposed to $24 \mathrm{oC}$ and $40 \mathrm{~min}$ after the start of temperature increase (temp). ABA (10-5 M) was added to the nutrient solution of control Steptoe and Az34 plants 20 min before the start and was present in the nutrient solution during the time of xylem sap collection. Statistically different values $(P<0.05)$ are labeled with different letters

Fig. 2.

$162 \times 64 \mathrm{~mm}(300 \times 300$ DPI $)$ 


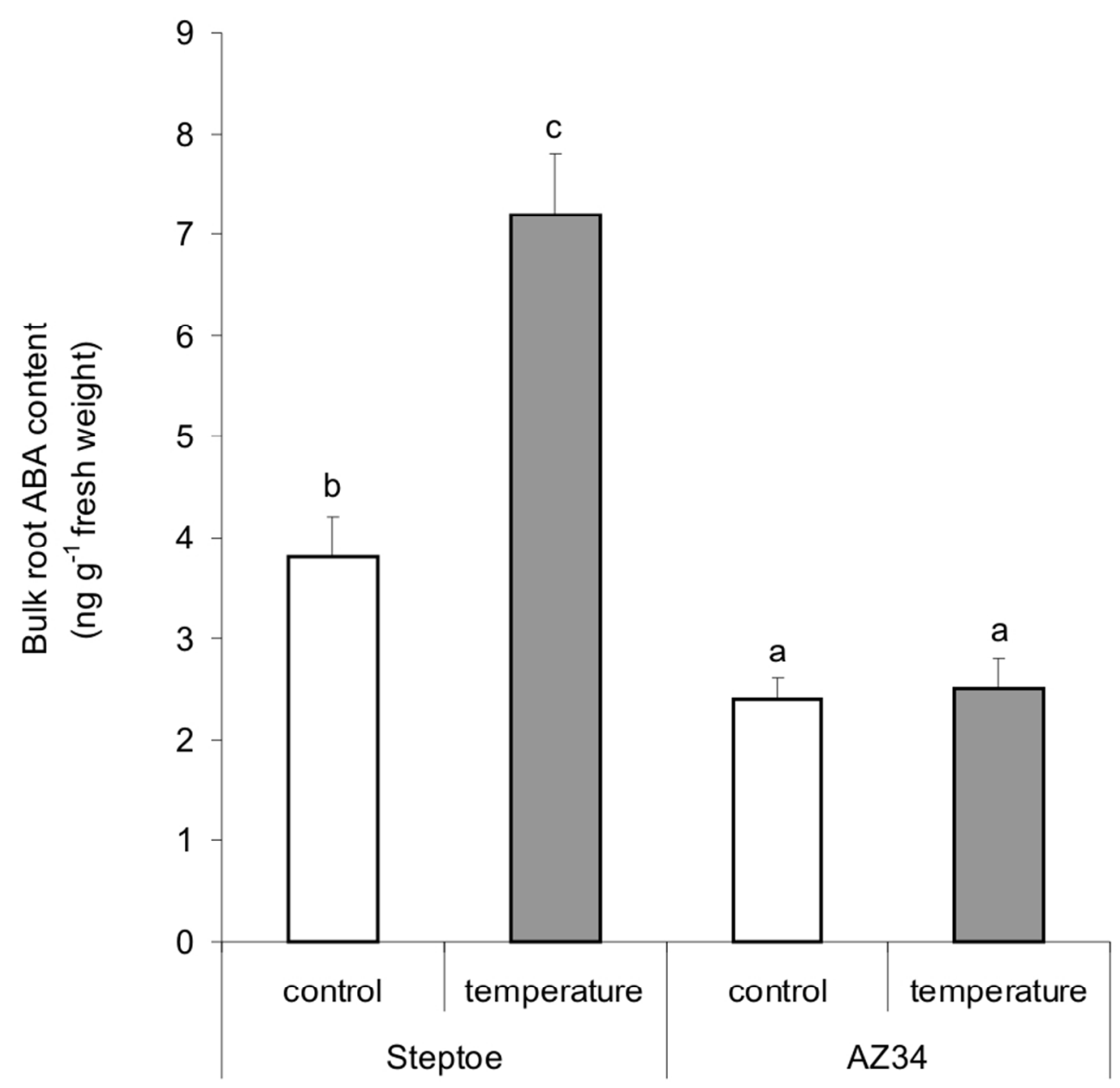

Bulk root $A B A$ content (mean values $\pm S E, n=5$ ) of Steptoe and Az34 plants measured in control plants exposed to $24 \mathrm{OC}$ and $40 \mathrm{~min}$ after the start of temperature increase (temp). Statistically different values $(P<0.05)$ are labeled with different letters

Fig 3

$79 \times 78 \mathrm{~mm}(300 \times 300$ DPI $)$ 